\title{
EL INCUMPLIMIENTO \\ DE LA LEY 30562 POR LAS EPS \\ Y LAS ASEGURADORAS \\ (LEY PERUANA)
}

\author{
BREACH OF LAW 30562 \\ BY EPSS AND INSURANCE COMPANIES \\ (PERUVIAN LAW)
}

ALONSO NÚÑEZ DEL PRADO SIMONS

\footnotetext{
*Abogado, cursó el Magíster en Derecho de la Integración y el de Derecho Constitucional, es Master of Business Administration (MBA) por el College of Insurance (hoy Saint John's University) de Nueva York, graduado en Lingüística y Literatura, además de en Filosofía, en que también cursó el Magíster. Es fundador y Director Ejecutivo del 'Observatorio de cumplimiento de planes de gobierno', profesor universitario, árbitro y conferencista internacional. Es autor del libro 'Los secretos de los seguros', coautor de otros y publica habitualmente en revistas jurídicas de varios países y en los principales diarios de Lima. Asimismo, fue presidente y fundador de la 'Asociación Peruana de Derecho de Seguros', Capítulo de AIDA en el Perú, actualmente es miembro del Consejo de la Presidencia de AIDA mundial y también del CILA y es director de varias entidades del sistema asegurador. Contacto: alonso.nezdelprado@gmail.com. https:// orcid.org/0000-0002-3482-7423
} 


\section{RESUMEN}

El presente artículo denuncia que la ley 30562 que está vigente desde mayo de 2017 no esté siendo aplicada porque se ha consultado el significado de dos términos que en realidad son bastante obvios para el sistema asegurador.

Palabras clave: Clase, producto y principio de mutualidad. 


\section{ABSTRACT}

This article denounces that Law 30562 that has been in force since May 2017 is not being applied because the meaning of two terms that are actually quite obvious to the insurance system has been consulted.

Keywords: Class, product and principle of mutuality. 
Los términos 'clase y 'producto' son usuales en marketing y también en estadística. La segunda acepción de la palabra 'clase' en el Diccionario de la Real Academia de la Lengua española (DRAE) dice 'conjunto de personas del mismo grado, calidad u oficio' y la octava indica: 'distinción, categoría'. Pues eso es lo que significa 'clase' para el caso que nos ocupa. La palabra 'producto' hace referencia a un objeto o servicio que está listo para su venta. En el caso de seguros un producto sería una póliza específica de seguro médico, automóviles o de cualquier otro ramo, usualmente con nombre propio.

El artículo 1 (Prohibición de recargos individuales) de la ley 30562, publicada el 18 de mayo de 2017, estableció que: "En la cobertura de las preexistencias cruzadas establecida en el artículo 118 de la Ley 29946, Ley del Contrato de Seguro, las empresas de seguro pueden efectuar recargos por clase o producto, de conformidad con el principio de mutualidad de los seguros dispuesto en el literal c) del artículo II del Título Preliminar de la Ley 29946. Se prohíbe el recargo individual, que se considera práctica prohibida".

Resulta obvio que este artículo se refiere a los recargos en los seguros médicos y coberturas de EPS y prohíbe que puedan hacerse individualmente incluso en caso de migraciones dentro de uno de los dos sistemas o entre ambos.

Si tenemos en cuenta que según el principio de mutualidad 'las pérdidas de pocos son cubiertas por la contribución de muchos' resulta bastante obvio qué significa que los recargos se pueden hacer por clase (los hombres, las mujeres, los comprendidos en determinados rangos de edad, etc.), pero no pueden hacerse a título individual, porque se rompería el principio de mutualidad. En el mercado de seguros esto no es una novedad. En todas partes del mundo no se pueden hacer recargos individuales en seguros médicos por la sencilla razón de que nadie se enferma voluntariamente. Los recargos individuales son permitidos en seguros como los de automóviles en que el mal record del chofer puede ser sancionado por ser en muchos casos de su responsabilidad, pero de ninguna manera en seguros médicos. El recargo por producto tiene sentido porque si una compañía tiene una póliza que comercializa y no tiene buenos resultados puede hacerle recargos, normalmente después de un año, pero a esa póliza que ha vendido a muchas personas y no a un individuo específico.

A pesar de que la norma y los términos son muy claros la Asociación Peruana de Empresas de Seguros (APESEG) decidió consultar sobre el significado de los términos 'clase' y 'producto' a la Superintendencia de 
Salud (SUSALUD) la que, increíblemente, no le ha contestado a pesar de que han reiterado la consulta por lo menos 6 veces en los últimos 2 años. En su descargo SUSALUD alega que a su vez le había trasladado la consulta al Ministerio de Salud (MINSA).

He tenido acceso a la documentación de interconsultas entre ambas instituciones y parecen de una película de Cantinflas. Es increíble que dos entidades estatales no estén en capacidad de responder una consulta con respuesta tan obvia y que una ley no se aplique como resultado de este nivel de ineficiencia. Esta demora ha llevado a que se pretenda imponer tarifas diferentes a los asegurados que vienen de otra compañía o EPS pretendiendo considerarlos como una clase, lo que es una evidente distorsión del objetivo de la norma.

Más absurdo todavía es que como APESEG no ha recibido respuesta a su consulta las EPS no estén aplicando el artículo 2 de la ley que no tiene ninguna relación con lo establecido en el artículo 1 y que las obliga a cobrar las mismas primas a todos sus afiliados. A la letra dice:

Artículo 2. Planes potestativos

Las EPS deben tener disponibles planes de salud potestativos, que son ofrecidos obligatoriamente por las EPS, que deben incluir como mínimo las mismas coberturas de los planes regulados ofrecidos por la EPS a la que pertenece el plan potestativo.

El plazo de migración del plan de EPS al plan de EPS potestativo es el establecido en la Ley 29344, Ley Marco de Aseguramiento Universal en Salud y el artículo 100 de su reglamento.

Las EPS, incluyendo sus planes potestativos, deben calcular su siniestralidad y los costos de todos sus planes de manera integral, de modo que todos sus afiliados paguen los mismos montos. Para ello, se entiende como una sola cartera la suma de los afiliados regulares y los afiliados potestativos.

Está claro que primero obliga a las EPS a que ofrezcan planes potestativos, regula el plazo de su migración y por último establece que las EPS deben calcular su siniestralidad y sus costos de manera integral de manera que todos sus afiliados (regulares y potestativos) paguen los mismos montos.

Como ya ocurrió respecto de la cobertura de las preexistencias con el artículo 118 de la Ley 29946 que terminó justamente con esta ley 30562, las EPS pretenden hacer una interpretación antojadiza y caprichosa sos- 
teniendo el absurdo que no tienen que cobrar las mismas primas a todos sus afiliados.

La pregunta se cae de madura: ¿Por qué SUSALUD se los permite? El hecho de que sea una Superintendencia nueva no es excusa para que afecten de esa manera los intereses de los afiliados que son su razón de existir. En realidad, corresponde una importante multa a todas las EPS que estén incumpliendo la norma.

Diversos expertos que nos han visitado de otros países del Derecho comparado han afirmado que las aseguradoras -y en nuestro caso también las EPS que están muy vinculadas a las primeras- "sólo aprenden a golpes" es decir siendo sancionadas con multas y mediante sentencias judiciales y resoluciones administrativas que además les indiquen que no pueden continuar interpretando a su conveniencia y haciendo lo que les viene en gana sólo por tener un inmenso poder económico. Es tiempo de que empecemos a enseñarles.

La aplicación de este artículo 2 traerá muchos beneficios para la mayor parte de afiliados a las EPS pues sus enfermedades podrán ser absorbidas por todos los clientes de la entidad y no sólo por sus compañeros de trabajo que en muchos casos son grupos muy pequeños que se ven afectados por la enfermedad de algunos.

San Isidro, 6 de septiembre de 2019 